\title{
Peningkatan harga diri melalui intervensi Cognitive behavioral therapy pada remaja korban bullying
}

\author{
Niken Yuniar Sari', Sri Maryuni² \\ 1,2 Program Studi Keperawatan, Fakultas Kesehatan, Universitas Mitra Indonesia. \\ Email: nikenyuniar@umitra.ac.id
}

\begin{abstract}
Cognitive behavioral therapy for bully-victims among adolescents in Islamic school, Indonesia
\end{abstract}

Background: Bullying is aggressive behavior, illegal, negative both physically and psychologically that is social environment and it was now are more prevalent in the education world. Sign of symptoms that by the bullying of them in the form of low self-esteem. On the sacrificial offering, health effort has never been bullying at the school health psychology as psychotherapy.

Purpose: Effectiveness of cognitive behavior therapy to bully-victims in adolescents.

Methods: The method of this study used case studies, with the amount of 21 respondents.

Results: The results of this study showed that teenagers bullying victims to the girl who the majority of the age of 14 years old, there was increased in self-esteem especially on aspects of cognitive and behavior after giving nursing intervention and cognitive behavior therapy.

Conclusion: The handling of this is cognitive behavior therapy that can be used as one of the preventive efforts of teenagers the bullying of low self-esteem.

\section{Keywords: Cognitive Behavioral Therapy; Bully-Victims; Adolescents; Islamic School}

Pendahuluan: Bullying merupakan suatu perilaku agresif, ilegal, negatif baik secara fisik maupun psikis yang ada dilingkungan sosial dan saat ini lebih banyak terjadi di dunia pendidikan. Tanda gejala yang muncul akibat bullying diantaranya berupa harga diri rendah. Upaya kesehatan pada korban bullying disekolah belum bersifat kesehatan psikologi seperti psikoterapi.

Tujuan: Hasil penanganan kasus ini bertujuan untuk menganalisis perubahan tanda gejala harga diri remaja santri korban bullying setelah diberikan intervensi Cognitive Behaviour Therapy menggunakan penerapan teori stres adaptasi Stuart.

Metode: Penanganan kasus ini menggunakan metode case study, dengan jumlah responden 21 orang.

Hasil: Hasil penanganan kasus menunjukan bahwa remaja santri korban bullying dengan jenis kelamin perempuan yang sebagian besar berusia 14 tahun, terjadi peningkatan harga diri terutama pada aspek kognitif dan perilaku setelah diberikan tindakan keperawatan ners dan ners spesialis berupa Cognitive Behavior Therapy.

Simpulan: Penanganan kasus ini berupa Cognitive Behavior Therapy dapat digunakan sebagai salah satu upaya preventif remaja santri remaja korban bullying terjadinya harga diri rendah.

\section{Kata Kunci: Harga Diri; Cognitive Behavioral Therapy; Remaja; Korban Bullying}

\section{PENDAHULUAN}

Bullying tidak terlepas dari adanya tiga pihak yang terlibat yaitu pelaku (bullies), korban (victim) dan orang yang berada dilokasi korban (bystander). Bullying merupakan suatu perilaku agresif, ilegal, negatif berupa fisik atau verbal dan saat ini terjadi di dunia pendidikan. Bullying banyak 
Peningkatan harga diri melalui intervensi Cognitive behavioral therapy pada remaja korban bullying

terjadi dilingkungan sekolah (Febriana, 2016). Hasil penelitian menunjukan bahwa $31,8 \%$ siswa Sekolah Dasar pernah mengalami bullying (Khairani, 2006) $67 \%$ pernah terjadi bullying di SMP dan SMA (Khairani, 2006; Sejiwa, 2008).

sekolah seperti pemukulan, penganiayaan dan penindasan. Data tersebut menunjukan bahwa bullying terjadi di sekolah (Irel, 2017).

Bullying banyak terjadi pada usia remaja dengan alasan yang ringan misalnya bercanda mengejek mengenai berat badan atau bentuk tubuh lainya. Perubahan yang tejadi dalam diri remaja menyebabkan perubahan emosi yang cenderung naik turun sehingga dapat memicu perasaan yang tidak terkontrol. Perubahan yang terjadi pada remaja merupakan sumber dari pembentukan harga diri (Wong, 2009).

Harga diri merupakan penilaian harga diri seseorang berdasarkan seberapa baik perilakunya yang sesuai dengan ideal diri. Harga diri berasal dari dua sumber yaitu diri sendiri dan orang lain. Harga diri adalah fungsi pertama dari dicintai dan mendapatkan rasa hormat dari orang lain. Harga diri meningkat seiring usia dan paling terancam selama masa remaja, ketika konsep diri sedang berubah dan banyak keputusan diri yang dilakukan (Kusumawati, \& Hartono, 2010). Evaluasi diri negatif ini mendorong pada terbentuknya pikiran negatif karena pasien tidak mampu berfikir logis, cemas saat berinteraksi dengan orang lain, konsentrasi yang menurun, perhatiannya yang mudah beralih dan bisa menimbulkan kegelisahan pada pasien sehingga bisa timbul perilaku gelisah. Perilaku yang terkait dengan harga diri rendah diantaranya juga berupa penurunan produktivitas, menarik diri, pesimis, bahkan sampai mencederai diri, orang lain dan perilaku merusak lainnya (Stuart, \& Sundeen, 2013).

Pembentukan harga diri berubah sesuai dengan perkembangan, dimana pada usia remaja sangat menyadari antara kemampuan dan pengakuan sosial, dan kemampuan remaja yang lebih besar. Harga diri selama masa remaja cenderung beresiko ketika remaja mengartikan identitas diri didalam kelompok sebayanya (Chinekesh, Kamalian, Eltemasi, \& Alavi, 2014). Berdasarkan pemaparan diatas maka dapat disimpulkan bahwa masa remaja mengalami perubahan seiring dengan meningkatnya harga diri, remaja akan semakin menyadari bahwa pengakuan teman sebaya atau lingkungan menjadi
$70,65 \%$ kasus tertinggi bullying di SMP dan SMA Yogyakarta (Mawardah, 2010).

Terdapat 1626 kasus bullying di Indonesia dan meningkat pada tahun 2009 menjadi 1891 kasus. Dimana 891 kasusnya terjadi di lingkungan

hal penting dalam kehidupanya. Cognitive Behaviour Therapy dianggap berpengaruh dalam mengubah harga diri klien dengan membantu individu mengidentifikasi pola kognitif dan pemikiran serta emosi yang berkaitan dengan perilaku (Bos, Muris, Mulkens, \& Schaalma, 2006; Romm, Rossberg, Hansen, Haug, Andreass, \& Melle, 2011).

Berdasarkan pemaparan di atas, maka peneliti dapat menyimpulkan masalah penelitian bahwa beberapa remaja santri korban bullying di pondok pesantren ada yang mengalami tanda dan harga diri rendah namun belum pernah dilakukan upaya promotif. Pelayanan kesehatan dan guru bimbingan konseling (BK) di Pondok Pesantren berfokus pada masalah remaja namun belum terkait pada aspek psikososial. Belum ada tindakan keperawatan yang dilakukan pada remaja yang mengalami tanda gejala harga diri rendah di Pondok Pesantren.

\section{METODE PENELITIAN}

Penanganan kasus ini menggunakan pendekatan case study yaitu remaja korban bulliying yang memiliki harga diri rendah di Pondok Pesantren Al Fattah Almuhajirun Natar pada bulan Mei 2019. Jumlah responden 21 orang. Penanganan kasus dilakukan dengan membandingkan harga diri remaja korban bullying sebelum dan sesudah diberikan intervensi Cognitive Behavior Therapy. Pengumpulan data menggunakan data primer dari format scanning dan instrument evaluasi (pre - post) tanda gejala harga diri rendah dan responden menyelesaikan sesi terapi kognitif perilaku.

Tindakan keperawatan yang diberikan berupa tindakan keperawatan ners dan tindakan keperawatan ners spesialis. Tindakan keperawatan ners berupa membina hubungan saling percaya antara perawat dengan remaja santri, diajarkan dan dilatih mengenal aspek positif yang dimiliki serta melatih kemampuan positif yang dimiliki. Tindakan keperawatan ners spesialis berupa terapi kognitif perilaku yang diberikan melalui 4 sesi yaitu; (1) mengidentifikasi pengalaman yang tidak menyenangkan dan menimbulkan pikiran otomatis

Niken Yuniar Sari', Sri Maryuni ${ }^{2}$ Program Studi Keperawatan, Fakultas Kesehatan, Universitas Mitra Indonesia Email: nikenyuniar@umitra.ac.id 
negatif dan perilaku negatif serta cara melawannya, (2) melawan pikiran otomatis negatif atau mengubah perilaku negatif kedua, (3) Memanfaatkan sistem pendukung, (4) Mengevaluasi manfaat latihan. Hasil yang akan disampaikan dalam penanganan kasus ini adalah karakteristik remaja santri, faktor predisposisi, faktor presipitasi, sumber koping serta perubahan tanda dan gejala harga diri remaja.

\section{HASIL}

Tabel 1. Karakteristik Remaja Korban Bullying $\mathrm{N}=\mathbf{2 1}$

\begin{tabular}{lcc}
\hline \multicolumn{1}{c}{ Karakteristik Klien } & Frekuensi (f) & Persentase (\%) \\
\hline Usia: & & \\
Usia 13 tahun & 8 & 38.1 \\
Usia 14 tahun & 13 & 61.9 \\
Jenis Kelamin: & & \\
Laki-laki & 9 & 42.8 \\
Perempuan & 12 & 57.1 \\
& & \\
Jumlah Saudara Kandung: & & 47.6 \\
Anak tunggal & 10 & 52.3 \\
1-22 orang & 11 & \\
Sosial ekonomi: & & 85.7 \\
Sedang & 18 & 14.2 \\
Tinggi & 3 & \\
\hline
\end{tabular}

Tabel 1. di atas menunjukkan bahwa sebagian besar remaja berusia 14 tahun yaitu sebanyak 13 (61.9\%), jenis kelamin paling banyak adalah perempuan yaitu 12 anak (57.1\%) jumlah saudara kandung paling banyak adalah 1 sampai 2 yaitu 11 orang (52.3\%) dan sebagian besar sosial ekonomi sedang yaitu 18 anak (85.7\%).

Niken Yuniar Sari', Sri Maryuni ${ }^{2}$ Program Studi Keperawatan, Fakultas Kesehatan, Universitas Mitra Indonesia 
Peningkatan harga diri melalui intervensi Cognitive behavioral therapy pada remaja korban bullying

Tabel 2. Distribusi Faktor Predisposisi Dengan Harga Diri Rendah N=21

\begin{tabular}{lcc}
\hline Faktor Predisposisi & Frekuensi (f) & Persentase (\%) \\
\hline Biologis: & & \\
Riwayat penyakit fisik & 7 & 33 \\
Riwayat merokok & 0 & 0 \\
Minum kopi & 9 & 42 \\
Riwayat minum alkohol & 0 & 0 \\
Riwayat dirawat di RS & 6 & 28 \\
Riwayat penyakit keturunan & 0 & 0 \\
Riwayat pola makan tidak teratur & 4 & 19 \\
Riwayat alergi makanan & 1 & 4.7 \\
& & \\
Psikologis: & & \\
Pengalaman yang tidak menyenangkan & 5 & 23 \\
Keinginan belum terpenuhi & 5 & 23 \\
Konsep diri negatif & 16 & 76 \\
Kepribadian tertutup & 4 & 19 \\
& & \\
Sosial: & & 0 \\
Putus sekolah & 0 & 0 \\
Ekonomi kurang & 0 & 0 \\
Konflik keluarga/lingkungan & 2 & 0 \\
Aktifitas spiritual kurang & 0 & \\
Tidak aktif dalam kegiatan sosial & 0 & \\
\hline
\end{tabular}

Tabel 2 diatas menunjukkan predisposisi terbanyak pada stressor psikologis berupa konsep diri negatif $(76 \%)$.

Tabel 3. Distribusi Faktor Presipitasi Dengan Harga Diri Rendah N=21

\begin{tabular}{lcc}
\hline Faktor Predisposisi & Frekuensi (f) & Persentase (\%) \\
\hline Biologis: & 0 & 0 \\
Penyakit fisik & 0 & 0 \\
Merokok & 9 & 42 \\
Minum kopi & 4 & 80 \\
Pola makan tidak teratur & & \\
& 5 & 23 \\
Psikologis: & 5 & 23 \\
Pengalaman yang tidak menyenangkan & 16 & 76 \\
Keinginan belum terpenuhi & 4 & 19 \\
Konsep diri negatif & & \\
Kepribadian tertutup & 0 & 0 \\
Sosial: & 0 & 0 \\
Putus sekolah & 2 & 9.5 \\
Ekonomi kurang & 0 & 0 \\
Konflik keluarga/lingkungan & & \\
Tidak aktif dalam kegiatan sosial &
\end{tabular}

Tabel 3. diatas menunjukkan presipitasi terbanyak pada stressor psikologis berupa konsep diri negatif (76\%).

Niken Yuniar Sari', Sri Maryuni ${ }^{2}$ Program Studi Keperawatan, Fakultas Kesehatan, Universitas Mitra Indonesia Email: nikenyuniar@umitra.ac.id 
Peningkatan harga diri melalui intervensi Cognitive behavioral therapy pada remaja korban bullying

Tabel 4. Sumber Koping Dengan Harga Diri Rendah N=21

Sumber Koping
Frekuensi (f)

Persentase (\%)

\begin{tabular}{|c|c|c|}
\hline \multicolumn{3}{|l|}{ Personal Ability: } \\
\hline $\begin{array}{l}\text { - Mengenal harga diri, mengungkapkan perasaan, mengenal } \\
\text { penyebab harga diri rendah dan perilaku yang diakibatkan }\end{array}$ & 5 & 23 \\
\hline $\begin{array}{l}\text { - Mengidentifikasi situasi kehidupan yang tidak mampu } \\
\text { dikontrol pasien }\end{array}$ & 2 & 9.5 \\
\hline $\begin{array}{l}\text { - Mendiskusikan pikiran negatif dan mengembangkan pikiran } \\
\text { positif }\end{array}$ & 0 & 0 \\
\hline $\begin{array}{l}\text { - Menggnakan kemampuan afirmasi pikiran dan harapan } \\
\text { positif dan mengontrol harga diri rendah }\end{array}$ & 0 & 0 \\
\hline $\begin{array}{l}\text { - Mengidentifikasi aktivitas yang dapat dilakukan untuk } \\
\text { mengontrol harga diri }\end{array}$ & 0 & 0 \\
\hline $\begin{array}{l}\text { - Melakukan aktivitas yang dapat dilakukan untuk mengontrol } \\
\text { harga diri }\end{array}$ & 0 & 0 \\
\hline Positive believe: & 21 & 100 \\
\hline $\begin{array}{l}\text { - Yakin dapat mengatasi perasaan harga diri } \\
\text { - Yakin dengan tenaga kesehatan }\end{array}$ & 21 & 100 \\
\hline Social Support: & 21 & 100 \\
\hline - Care giver: Ibu & 21 & 100 \\
\hline $\begin{array}{l}\text { - Ikut dalam kelompok yang sama } \\
\text { - Terdapat kader kesehatan jiwa (KKJ) }\end{array}$ & 21 & 100 \\
\hline Material Assets: & 13 & 61 \\
\hline - Memiliki BPJS/Jamkesmas & 21 & 100 \\
\hline $\begin{array}{l}\text { - Memiliki tabungan } \\
\text { - Fasilitas kesehatan (RS, klinik, puskesmas) terjangkau }\end{array}$ & 21 & 100 \\
\hline
\end{tabular}

Tabel 4. didapatkan hasil bahwa personal ability remaja paling banyak yaitu mengenal harga diri, mengungkapkan perasaan, mengenal penyebab harga diri rendah dan perilaku yang diakibatkan yaitu sebanyak 5 orang $(23 \%)$, seluruh remaja yakin dapat mengatasi perasaan harga diri rendah, yakin dengan tenaga kesehatan dapat membantunya, dan memiliki jaminan kesehatan serta fasilitas kesehatan baik rumah sakit atau puskesmas terjangkau dari tempat tinggal remaja.

Tabel 5. Tanda dan Gejala Harga Diri Rendah Dengan Mendapatkan Cognitive Behavior Therapy N=21

\begin{tabular}{lccc}
\hline Tanda dan Gejala & \multicolumn{3}{c}{ Frekuensi } \\
\cline { 2 - 4 } & Sebelum & Setelah & Selisih \\
\hline HDR & 18.22 & 2.25 & 15.87 \\
Kognitif (9) & 16.66 & 2 & 14.66 \\
Afektif (6) & 16.66 & 3.66 & 12.66 \\
Fisiologis (6) & 16.93 & 2 & 14.86 \\
Perilaku (15) & 7 & 0.66 & 6.33 \\
Sosial (3) & & & \\
\hline
\end{tabular}

Tabel 5. diatas menunjukkan bahwa secara keseluruhan terdapat penurunan tanda dan gejala, dimana

Niken Yuniar Sari', Sri Maryuni ${ }^{2}$ Program Studi Keperawatan, Fakultas Kesehatan, Universitas Mitra Indonesia Email: nikenyuniar@umitra.ac.id 
Peningkatan harga diri melalui intervensi Cognitive behavioral therapy pada remaja korban bullying

untuk harga diri rendah penurunan tertinggi terdapat pada aspek kognitif sebesar 15,87 poin diikuti oleh Perilaku sebesar 14,86 poin diikuti fisiologis, afektif dan sosial.

\section{PEMBAHASAN}

Tanda dan gejala harga diri rendah pada remaja korban bullying yang diukur meliputi tanda gejala kognitif, afektif, fisiologis, perilaku dan sosial. Nilai diukur sebelum dan sesudah diberikan tindakan keperawatan ners, ners spesialis Cognitive Behavior Therapy. Adapun indikator tanda dan gejala harga diri rendah pada pada kognitif meliputi 9 indikator yaitu; (1) penolakan terhadap kemampuan diri, (2) pandangan hidup yang pesimis, (3) merasa tidak berguna, (4) merasa menilai diri negatif, mengkritik diri, (5) kurang konsentrasi, (6) merasa tidak mampu melakukan sesuatu, (7) merasa tidak mempunyai kemampuan positif, (8) menilai diri tidak berguna, (9) membanggakan diri berlebihan. Afektif terdiri dari 6 indikator yaitu; (1) merasa tidak berarti, (2) merasa malu, (3) merasa sedih, (4) rasa kesal, (5) marah, (6) merasa gagal. Terdapat 6 indikator untuk fisiologis diantaranya; (1) selera makan menurun/meningkat, (2) sulit tidur, (3) lemas, (4) nyeri kepala, (5) mual (6) postur tubuh membungkuk. Perilaku terdiri 15 yaitu; (1) kontak mata kurang, ( 2) murung, (3) berjalan memunduk dan postur tubuh menunduk, (4) menghindari orang lain, lebih senang menyendiri, (5) bicara pelan dan lebih banyak diam, (6) nada suara lemah, (7) aktivitas menurun (8) produktivitas menurun (9) bergerak lamban (10) bicara pelan, (11) merusak diri, (12) perilaku tidak asertif, (13) pasif, (14) mengkritik orang lain, (15) kurang memperhatikan penampilan/penampilan berlebihan. Sosial terdiri dari 3 yaitu; (1) lebih senang menyendiri, (2) membatasi interaksi dengan orang lain, (3) lebih banyak diam.

Hasil penelitian menunjukan bahwa remaja yang mendapatkan Cognitive Behavior Therapy mengalami perubahan, terutama pada kognitif dan perilaku yang dilakukan pada penelitian ini diikuti oleh santri kelas VIII dimana santri berada pada tahap perkembangan remaja. Hal ini sesuai dengan penelitian sebelumnya yang menunjukan bahwa Cognitive Behavior Therapy dapat meningkatkan kemampuan kognitif dan perilaku pasien dengan harga diri rendah (Wahyuningsih, 2009). Penelitian lainnya menyatakan bahwa pasien yang mendapat tindakan keperawatan ners dan terapi perilaku mengalami peningkatan kemampuan pasien dalam melakukan perilaku positif ketika harga diri rendah muncul (Nyumirah, 2013).

Hasil penanganan kasus pada remaja yang mendapatkan tindakan keperawatan ners terjadi perubahan secara bermakna. Terjadi peningkatan harga diri pemberian tindakan keperawatan ners, pada remaja dengan cara membantu untuk Setelah diberikan tindakan keperawatan ners remaja mampu mengidentifikasi kemampuan positif yang dimiliki dan melatih kemampuan yang dipilih dan menerapkan kemampuan remaja tersebut dalam jadwal harian remaja. Hal ini agar meningkatkan kemampuan remaja (Kristyaningsih, Keliat, \& Helena, 2009).

Cognitive Behavior Therapy penting untuk diberikan guna membantu remaja santri korban bullying melawan pikiran otomatis negatifnya. Hasil evaluasi menunjukan bahwa terapi ini memberikan dampak yang lebih efektif menurunkan di respon kognitif. Hal ini dapat dijelaskan karena terapi kognitif perilaku adalah suatu terapi psikososial yang mengintegrasikan modifikasi perilaku melalui pendekatan restrukturisasi kognitif. Terapi kognitif perilaku mempunyai tujuan untuk merubah pola pikir negatif menjadi positif sehingga perilaku maladaptif yang timbul akibat pola pikir yang salah juga akan berubah menjadi perilaku yang adaptif (Martin, \& Dahlen, 2004).

Respons kognitif memegang peran sentral dalam proses adaptasi, dimana faktor kognitif mempengaruhi dampak suatu kejadian yang penuh dengan stress, memilih koping yang akan digunakan, dan reaksi emosi, fisiologi, perilaku, dan sosial seseorang. Selain itu respons perilaku merefleksikan respons emosi dan fisiologis sebagai hasil analisis kognitif dalam menghadapi suatu situasi yang penuh stress (Stuart, \& Sundeen, 2013).

Terapi kognitif perilaku merupakan intervensi yang paling tepat untuk meningkatkan harga diri individu (Guindon, 2010). Cognitive Behaviour Therapy dianggap dapat mengubah harga diri klien dengan membantu individu menentukan pola kognitif dan pemikiran serta emosi yang berhubungan dengan perilaku (Birchwood, Fowler, \& Jackson, 2000; Bechdolf, Wagner, Veith, Ruhrmann, Pukrop, Brockhaus, \& Bottlender,

Niken Yuniar Sari', Sri Maryuni ${ }^{2}$ Program Studi Keperawatan, Fakultas Kesehatan, Universitas Mitra Indonesia Email: nikenyuniar@umitra.ac.id 
Peningkatan harga diri melalui intervensi Cognitive behavioral therapy pada remaja korban bullying

2007). Cognitive behavior therapy meningkatkan kemampuan kognitif dan perilaku klien skizofrenia dengan harga diri rendah (Sudiatmika, Keliat, \& Wardani, 2013). menunujukan bahwa Terapi kognitif perilaku yang diberikan pada pasien gagal ginjal kronik berpengaruh terhadap perubahan harga diri klien dengan gagal ginjal kronik (Maryatun, \& Ningsih, 2019).

\section{SIMPULAN}

Berdasarkan diskusi diatas dapat disimpulkan bahwa terjadi penurunan tanda dan gejala harga diri rendah remaja santri korban bulyying setelah diberikan tindakan keperawatan ners.

\section{SARAN}

Studi kasus ini menyarankan agar latihan Cognitive Behavior Therapy diberikan kepada remaja santri korban bullying.

\section{DAFTAR PUSTAKA}

Bechdolf, A., Wagner, M., Veith, V., Ruhrmann, S., Pukrop, R., Brockhaus, D. A., \& Bottlender, R. (2007). Randomized controlled multicentre trial of cognitive behaviour therapy in the early initial prodromal state: effects on social adjustment post treatment. Early intervention in psychiatry,1(1), 71-78.

Birchwood, M. J., Fowler, D., \& Jackson, C. (Eds.). (2000).Early intervention in psychosis: a guide to concepts, evidence and interventions (Vol. 71). Wiley.

Bos, A. E., Muris, P., Mulkens, S., \& Schaalma, H. P. (2006). Changing self-esteem in children and adolescents: A roadmap for future interventions. Netherlands Journal of Psychology,62(1), 26-33.

Chinekesh, A., Kamalian, M., Eltemasi, M., Chinekesh, S., \& Alavi, M. (2014). The effect of group play therapy on social-emotional skills in pre-school children. Global Journal of Health Science, 6(2), 163.

Febriana, B. (2016). Pengaruh Terapi Kognitif Terhadap Harga Diri Remaja Korban Bullying. Jurnal IImu Keperawatan, 4(1), 73-84.
Guindon, M. H. (2010). What do we know about self-esteem interventions. Self-esteem across the lifespan: Issues and interventions, 3-25.

Irel, I. R. (2017). Hubungan Sense of Self dengan Kecenderungan Perilaku Bullying pada Siswa SMA di Jakarta.PSIKODIMENSIA, 16(1), 91106.

Khairani, A. (2006). Modul program pendidikan: pencegahan perilaku bullying di sekolah dasar (Doctoral dissertation, FPsi-UI).

Kristyaningsih, T., Keliat, B. A., \& Helena, N. (2009).Pengaruh Terapi Kognitif Terhadap Harga Diri dan Kondisi Depresi pada Penderita Gagal Ginjal Kronik di Ruang Haemodialisa RSUP Fatmawati Jakarta (Doctoral dissertation, Tesis, Jakarta).

Kusumawati, F., \& Hartono, Y. (2010). Buku ajar keperawatan jiwa. Jakarta: Salemba Medika, 59-75.

Martin, R. C., \& Dahlen, E. R. (2004). Irrational beliefs and the experience and expression of anger. Journal of Rational-Emotive and Cognitive-Behavior Therapy, 22(1), 3-20.

Maryatun, S., \& Ningsih, N. (2019, February). Pengaruh cognitive behaviour therapy (CBT) terhadap perubahan harga diri pasien perilaku kekerasan dengan aplikasi. In Seminar Nasional Keperawatan (No. 2, pp. 193-198).

Mawardah, M. (2010). Hubungan antara Regulasi Emosi dengan Kecenderungan Perilaku Bullying. Jurnal Ilmiah Psyche/llmu Psikologi, 4(2).

Nyumirah, S. (2013). Peningkatan kemampuan interaksi sosial (kognitif, afektif dan perilaku) melalui penerapan terapi perilaku kognitif di rsj $\mathrm{dr}$ amino gondohutomo semarang. Jurnal keperawatan jiwa, 1(2).

Romm, K. L., Rossberg, J. I., Hansen, C. F., Haug, E., Andreassen, O. A., \& Melle, I. (2011). Selfesteem is associated with premorbid adjustment and positive psychotic symptoms in early psychosis. BMC psychiatry, 11(1), 136.

Niken Yuniar Sari', Sri Maryuni ${ }^{2}$ Program Studi Keperawatan, Fakultas Kesehatan, Universitas Mitra Indonesia Email: nikenyuniar@umitra.ac.id 
Sejiwa, Y. S. J. A. (2008). Bullying. Mengatasi Kekerasan. Jakarta: PT Grasindo.

Stuart, G. W., \& Sundeen, S. J. (2013). Principles and practice of psychiatric nursing. St Louis, Missouri.

Sudiatmika, I. K., Keliat, B. A., \& Wardani, I. Y. (2013). Efektivitas cognitive behaviour therapy dan rational emotive behaviour therapy terhadap gejala dan kemampuan mengontrol emosi pada klien perilaku kekerasan. Jurnal Keperawatan Jiwa, 1(1).
Wahyuningsih, D. (2009). Pengaruh assertiveness training (AT) terhadap perilaku kekerasan pada klien skizoprenia di RSUD Banyumas (Doctoral dissertation, Universitas Indonesia. Fakultas IImu Keperawatan).

Wong, D. L. (2009). Buku ajar keperawatan pediatrik vol 1 wong. EGC. 